\title{
Temperature monitoring during ECMO: an in vitro study
}

\author{
F Mojoli", S Bianzina, L Caneva, G Tavazzi, S Mongodi, M Pozzi, A Orlando, A Braschi \\ From ESICM LIVES 2015 \\ Berlin, Germany. 3-7 October 2015
}

\section{Introduction}

The need of heat exchanger in the ECMO circuit is controversial. Moreover, how to monitor patient central temperature during extracorporeal support is still not clear, but potentially useful for the detection of "unexpressed" fever, eventually related to septic complications.

\section{Objectives}

We conducted two in vitro experiments to estimate ECMO heat dispersion and obtain clinical information regarding patient central temperature during extracorporeal support.

\section{Methods}

Experiment A. We analyzed heat dispersion of an ECMO circuit (Maquet Rotaflow PLS System) at 36 combinations of blood flow (BF 1-3-5 L/min), gas flow (GF 0-5$10 \mathrm{~L} / \mathrm{min}$ ) and set temperature (T set $36-37-38-39{ }^{\circ} \mathrm{C}$ ).
In any condition, heat dispersion was considered equal to the power (Watts) generated by the heat exchanger at the steady state, defined as stable temperature throughout the circuit.

Experiment B. By a reservoir bag, we connected two circuits (pump+oxygenator+heat exchanger), one simulating the patient and the other the ECMO circuit. Patient and ECMO circuit T set ranged $36-39{ }^{\circ} \mathrm{C}$ and $35-39{ }^{\circ} \mathrm{C}$, respectively, for overall 63 conditions; $\Delta \mathrm{T}$ was patient - ECMO circuit $\mathrm{T}$ set difference. The power generated by the two heat exchangers (Watts, W) was recorded at constant patient $\mathrm{BF}(5 \mathrm{~L} / \mathrm{min})$ and ECMO $\mathrm{BF}$ and $\mathrm{GF}(3 \mathrm{~L} / \mathrm{min}$ each).

\section{Results}

A) Overall, BF was $3.0 \pm 1.7 \mathrm{~L} / \mathrm{min}$, GF $5.0 \pm 4.1 \mathrm{~L} / \mathrm{min}$, pump rate $1299 \pm 615 \mathrm{rpm}, \mathrm{T}$ set $37.5 \pm 1.1{ }^{\circ} \mathrm{C}$ and circuit

Figure 1
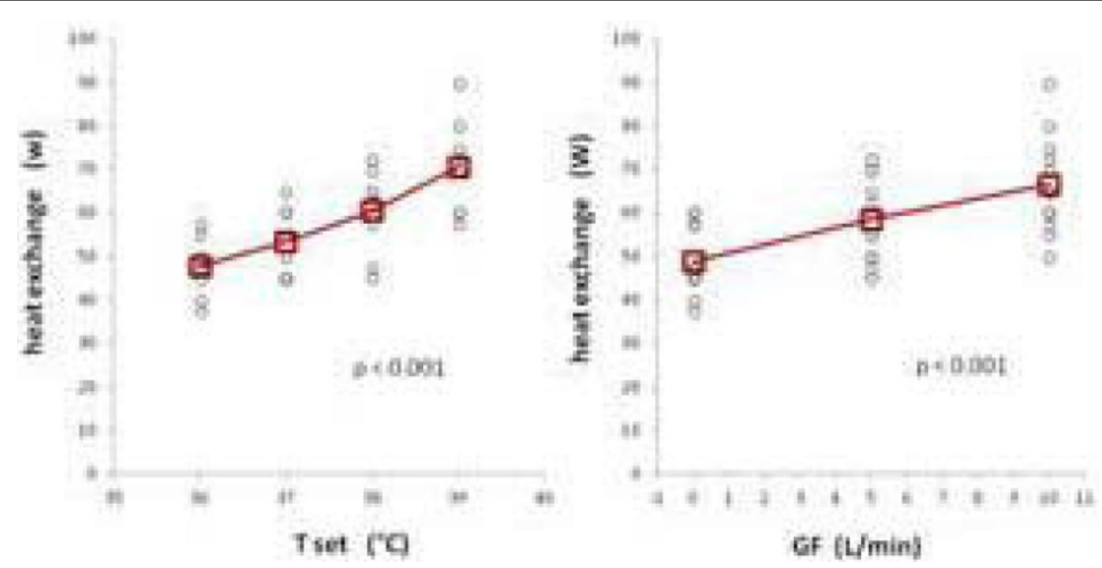

Anesthesia and Intensive Care, Fondazione IRCCS Policlinico S. Matteo,

University of Pavia, Pavia, Italy

(0) 2015 Mojoli et al.; This is an Open Access article distributed under the terms of the Creative Commons Attribution License (http:// creativecommons.org/licenses/by/4.0), which permits unrestricted use, distribution, and reproduction in any medium, provided the original work is properly cited. 


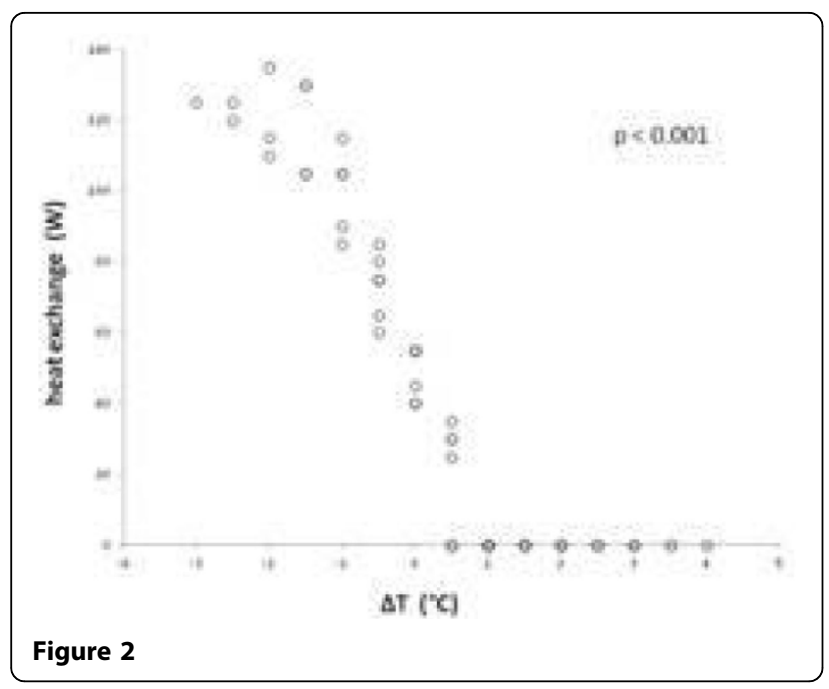

heat dispersion $58 \pm 12 \mathrm{~W}$ (range 37.5-90), corresponding to a supposed patient metabolic consumption of $1196 \pm$ $246 \mathrm{Kcal} /$ die (range 774-1857) in case of heat exchanger absence or inactivation. It was affected by GF and $\mathrm{T}(\mathrm{p}<$ $0.001)$, but not by BF $(\mathrm{p}=0.9)$ (Figure 1$)$.

B) For $\Delta \mathrm{T}>0$ heat exchanger did not generate energy, while for $\Delta \mathrm{T}<0$ it supplied energy proportional to $\Delta \mathrm{T}$ $(\mathrm{p}<0.001)$. For $\Delta \mathrm{T}=0$, heat exchanger power was $49 \pm$ $7 \mathrm{~W}$ (range 40-55) (Figure 2).

\section{Conclusions}

ECMO heat dispersion depends on GF and temperature, but not on BF. Therefore, heat exchanger should be considered also during low $\mathrm{BF} /$ high GF $\mathrm{ECCO}_{2} \mathrm{R}$. T set on heat exchanger is well matched with patient central temperature when its power is in the 40-55 W range, whereas lower power values may be associated to patient "unexpressed" fever.

Published: 1 October 2015

doi:10.1186/2197-425X-3-S1-A506

Cite this article as: Mojoli et al:: Temperature monitoring during ECMO: an in vitro study. Intensive Care Medicine Experimental 2015 3(Suppl 1): A506.

\section{Submit your manuscript to a SpringerOpen ${ }^{\mathcal{O}}$ journal and benefit from:}

- Convenient online submission

- Rigorous peer review

- Immediate publication on acceptance

- Open access: articles freely available online

- High visibility within the field

- Retaining the copyright to your article

Submit your next manuscript at $>$ springeropen.com 